\title{
Influence of glucocorticoids on markers of inflammation in community-acquired pneumonia
}

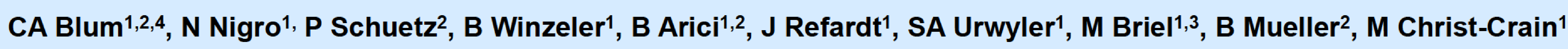

${ }^{1}$ University Hospital Basel, Departments of Endocrinology, Diabetology and Metabolism, Internal Medicine and Clinical Research, Switzerland; ${ }^{2}$ Medical University Clinic, Kantonsspital Aarau, Switzerland; ${ }^{3}$ Department of Clinical Epidemiology and Biostatistics, McMaster University, Hamilton, Ontario, Canada; ${ }^{4}$ Service d'Accueil des Urgences, CHU Pitié-Salpêtrière, Paris, France

\section{BACKGROUND}

Glucocorticoids are frequently prescribed in inflammatory diseases. It has been suggested that glucocorticoids interfere with inflammatory marker levels. ${ }^{1,2,3}$

We investigated the influence of prednisone on classical and novel inflammatory markers in community-acquired pneumonia (CAP).

\section{METHODS}

We evaluated levels of $\mathrm{C}$-reactive protein (CRP), procalcitonin, leukocyte and neutrophil count in a prospective randomized, double-blind, placebo-controlled multicenter trial which compared prednisone $50 \mathrm{mg}$ for seven days to placebo in patients hospitalized with CAP. ${ }^{4}$ We performed Mann-Whitney-U-tests to compare biomarker levels between groups on day 1 before the first administration of prednisone and thereafter on days 3, 5, 7 and discharge.

\section{RESULTS}

335 patients in the prednisone group and 350 patients in the placebo group were evaluated.

At baseline, all investigated marker levels did not differ between prednisone and placebo group.

At days 3, 5, and 7, CRP levels were significantly lower in the prednisone group than in the placebo group $(p<0.001$ for each time point; see figure 1).

For procalcitonin, this attenuating effect of glucocorticoids on circulating levels was not visible $(p<0.05$ for all time points; see figure 2$)$.

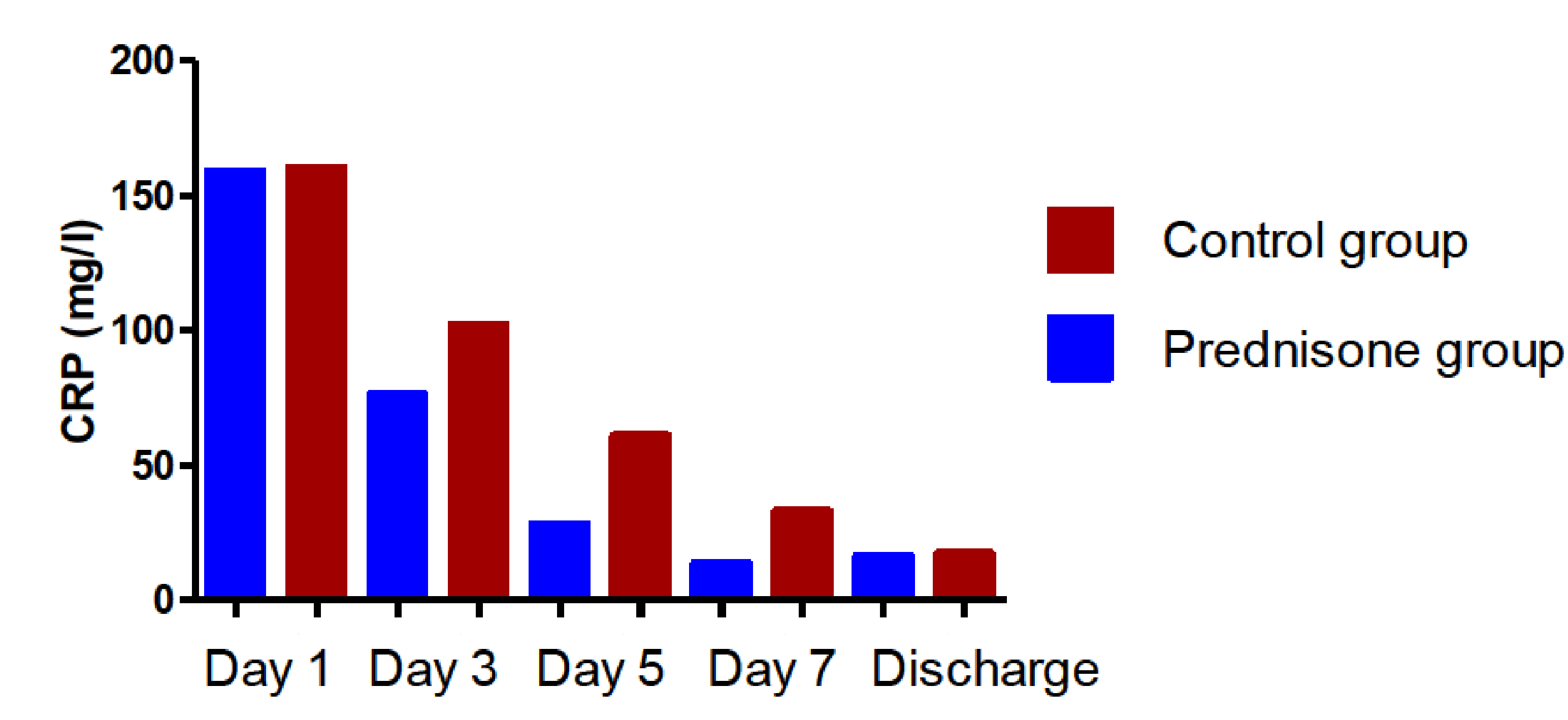

Figure 1. CRP levels during hospitalization

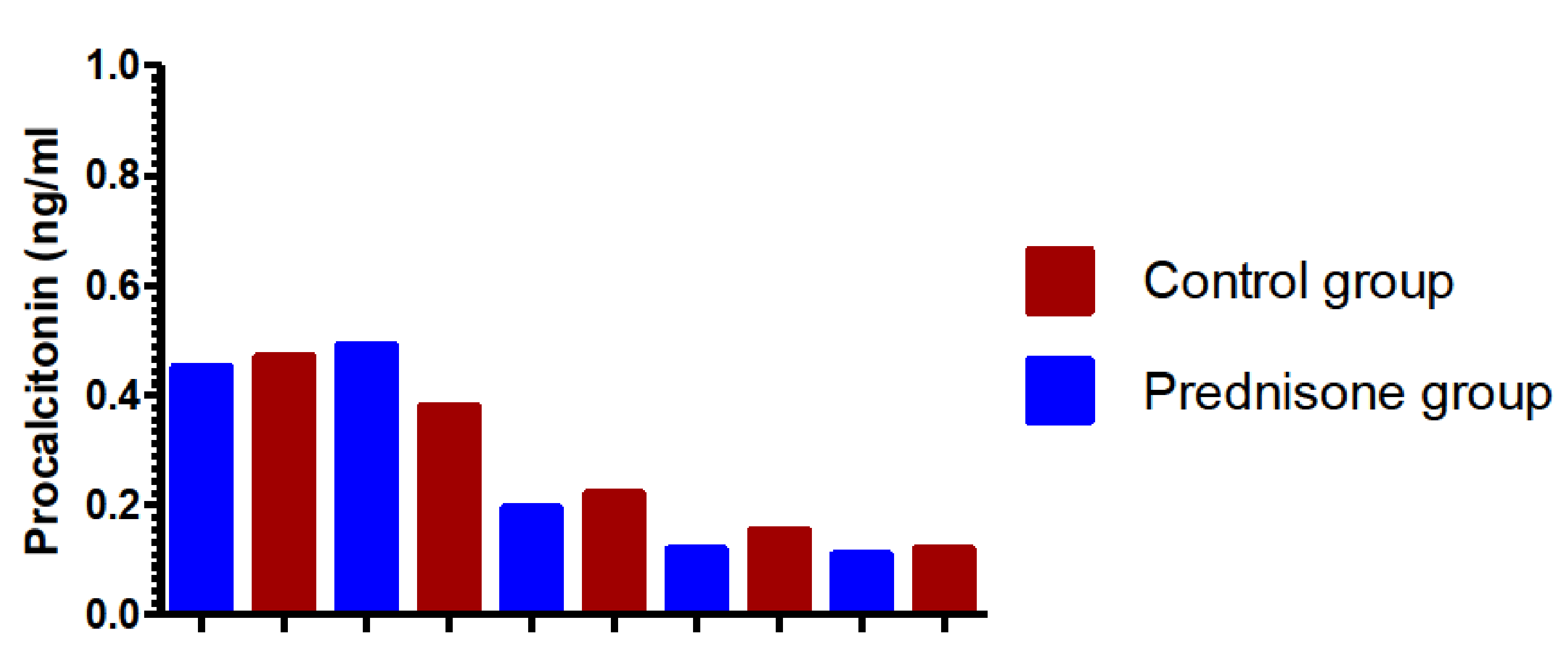

Day 1 Day 3 Day 5 Day 7 Discharge

Figure 2. Procalcitonin levels during hospitalization

Leukocyte and neutrophil count were higher in the prednisone group during administration of glucocorticoids ( $p<0.0001$ for all time points including discharge (see figures 3 and 4 ).

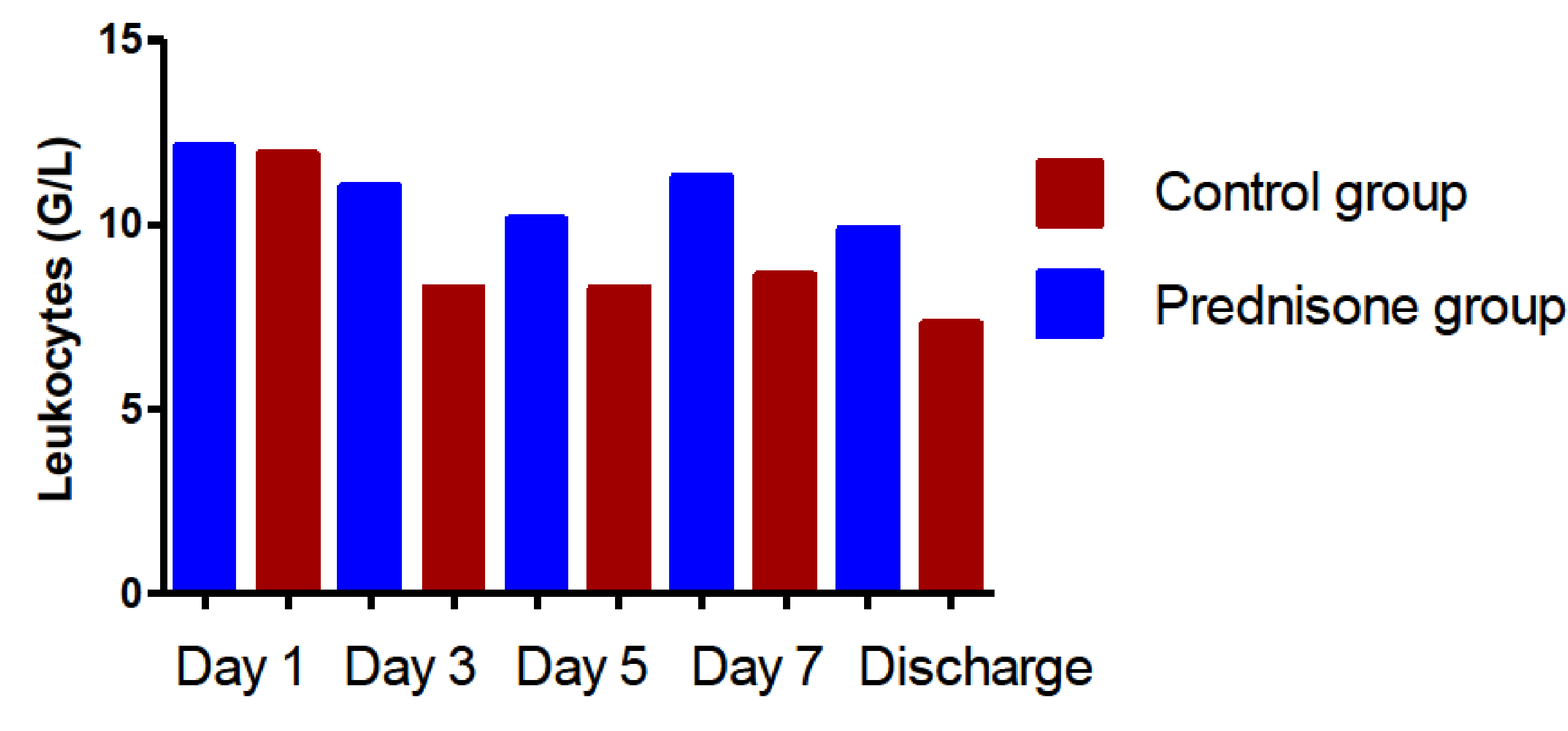

Figure 3. Leukocyte count during hospitalization

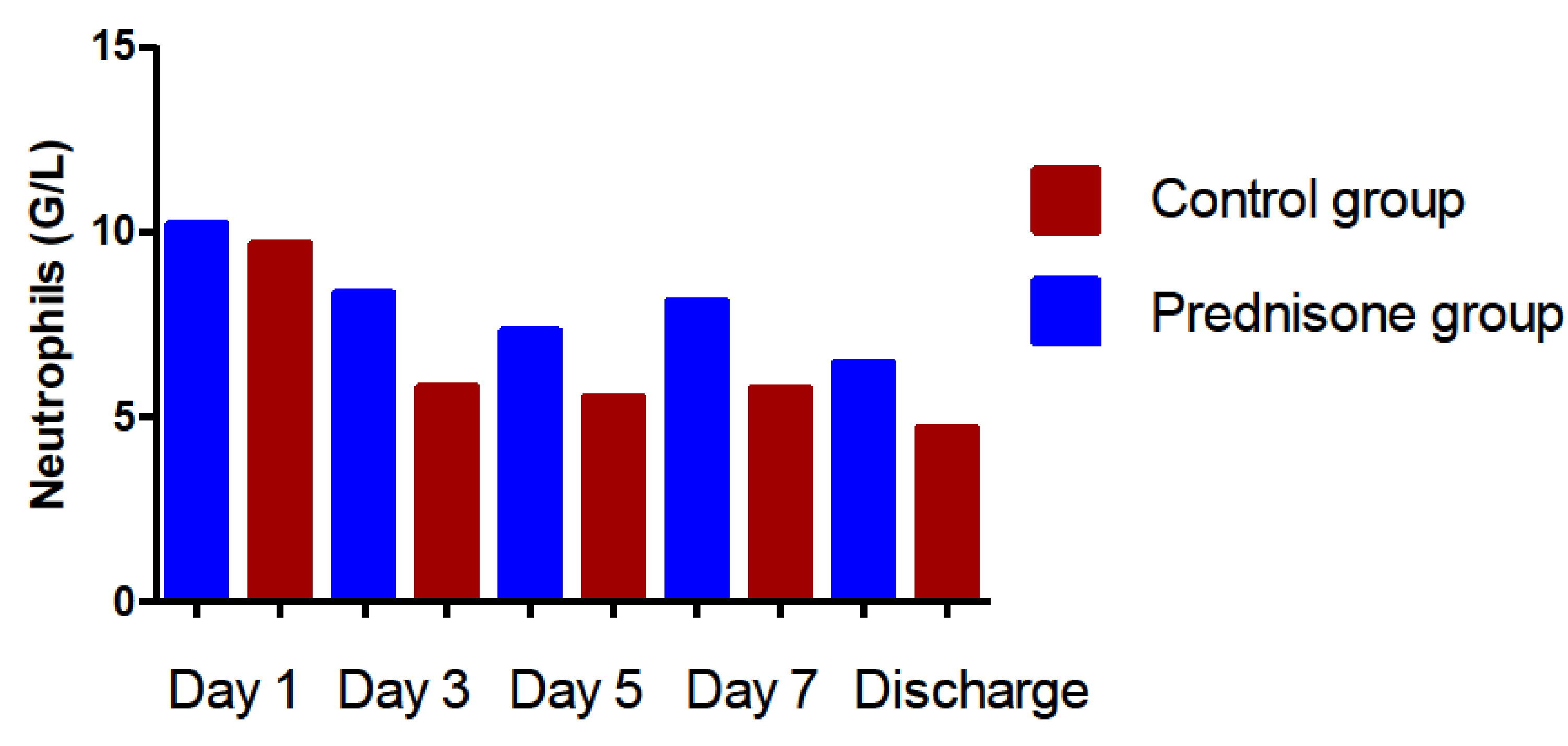

Figure 4. Neutrophil count during hospitalization

\section{CONCLUSION}

\section{Administration of glucocorticoids in patients with CAP}

- lowers CRP levels

- increases leukocyte and neutrophil count

- does not influence procalcitonin levels

Therefore, procalcitonin may be a more adequate inflammatory marker to measure treatment response in patients with an infectious disease receiving glucocorticoids.

\section{REFERENCES}

1. Müller B et al. High circulating levels of the IL-1 type II decoy receptor in critically ill patients with sepsis: association of high decoy receptor levels with glucocorticoid administration. J Leukoc Biol. 2002 Oct;72(4):643-9.

2. Perren $A$ et al. Influence of steroids on procalcitonin and $C$-reactive protein in patients with COPD and communityacquired pneumonia. Infection. 2008 Mar;36(2):163-6. doi: 10.1007/s15010-007-7206-5.

3. Kutz $A$ et al. Pre-analytic factors and initial biomarker levels in community-acquired pneumonia patients. BMC Anesthesiol. 2014 Nov 15;14:102.

4. Blum CA et al. Adjunct prednisone therapy for patients with community-acquired pneumonia: a multicentre, double-blind, randomised, placebo-controlled trial. Lancet. 2015 Jan 16. pii: S0140-6736(14)62447-8.

\section{CORRESPONDING AUTHOR}

Dr. med. Claudine Blum

Service d'Accueil des Urgences

CHU Pitié-Salpêtrière

Paris, France

claudineblum@yahoo.com

0041763030757 